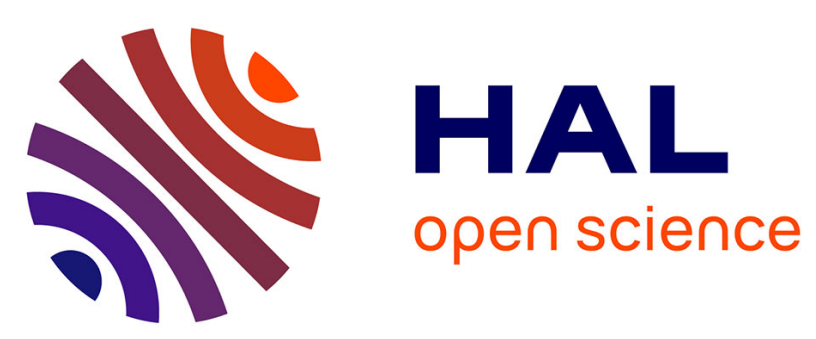

\title{
Extensive human-mediated jump dispersal within and across the native and introduced ranges of the invasive termite Reticulitermes flavipes
}

Pierre-André Eyer, Alexander Blumenfeld, Laura Johnson, Elfie Perdereau, Phillip Shults, Shichen Wang, Franck Dedeine, Simon Dupont, Anne-Geneviève Bagnères, Edward Vargo

\section{To cite this version:}

Pierre-André Eyer, Alexander Blumenfeld, Laura Johnson, Elfie Perdereau, Phillip Shults, et al.. Extensive human-mediated jump dispersal within and across the native and introduced ranges of the invasive termite Reticulitermes flavipes. 2020. hal-03003416

\author{
HAL Id: hal-03003416 \\ https://hal.science/hal-03003416
}

Preprint submitted on 13 Nov 2020

HAL is a multi-disciplinary open access archive for the deposit and dissemination of scientific research documents, whether they are published or not. The documents may come from teaching and research institutions in France or abroad, or from public or private research centers.
L'archive ouverte pluridisciplinaire HAL, est destinée au dépôt et à la diffusion de documents scientifiques de niveau recherche, publiés ou non, émanant des établissements d'enseignement et de recherche français ou étrangers, des laboratoires publics ou privés. 


\title{
Extensive human-mediated jump dispersal within and across the native and introduced ranges of the invasive termite Reticulitermes flavipes
}

Pierre-André Eyer ${ }^{1}$, Alexander Blumenfeld ${ }^{1}$, Laura Johnson ${ }^{2}$, Elfie Perdereau ${ }^{3}$, Phillip Shults $^{1}$, Shichen Wang ${ }^{1}$, Franck Dedeine ${ }^{4}$, Simon Dupont ${ }^{5}$, Anne-Geneviève Bagnères ${ }^{6}$, and Edward Vargo ${ }^{7}$

${ }^{1}$ Texas A\&M University College Station

${ }^{2}$ University of Wyoming

${ }^{3}$ Institut de Recherche sur la Biologie de l'Insecte

${ }^{4}$ Universite de Tours

${ }^{5}$ IRBI

${ }^{6}$ Affiliation not available

${ }^{7}$ Texas A\&M University

November 13, 2020

\begin{abstract}
As native ranges are often geographically structured, invasive species originating from a single source population only carry a fraction of the genetic diversity present in their native range. This invasion pathway is thus often associated with a drastic loss of genetic diversity resulting from a founder event. However, the fraction of diversity brought to the invasive range may vary under different invasion histories, increasing with the size of the propagule, the number of re-introduction events, and/or the total genetic diversity represented by the various source populations in a multiple-introduction scenario. In this study, we generated a SNP dataset for the invasive termite Reticulitermes flavipes from 23 native populations in the eastern United States and six introduced populations throughout the world. Using population genetic analyses and approximate Bayesian computation $(\mathrm{ABC})$, we investigated its worldwide invasion history. We found a complex invasion pathway with multiple events out of the native range and bridgehead introductions from the introduced population in France. Our data suggest that extensive long-distance jump dispersal appears common in both the native and introduced ranges of this species, likely through human transportation. Overall, our results show that similar to multiple introduction events into the invasive range, admixture in the native range prior to invasion can potentially favor invasion success by increasing the genetic diversity that is later transferred to the introduced range.
\end{abstract}

Extensive human-mediated jump dispersal within and across the native and introduced ranges of the invasive termiteReticulitermes flavipes

Pierre-André Eyer ${ }^{1+}$, Alexander J. Blumenfeld ${ }^{1+}$, Laura N. L. Johnson ${ }^{1,2}$, Elfie Perdereau ${ }^{3}$, Phillip Shults ${ }^{1}$, Shichen Wang ${ }^{4}$, Franck Dedeine ${ }^{3}$, Simon Dupont ${ }^{3}$, Anne-Genevieve Bagneres ${ }^{3,5 \#}$, Edward L. Vargo ${ }^{1 \#}$

${ }^{1}$ Department of Entomology, 2143 TAMU, Texas A\&M University, College Station, Texas, 77843-2143, USA

${ }^{2}$ Department of Veterinary Sciences, University of Wyoming, Laramie, Wyoming, 82070, USA

${ }^{3}$ IRBI, UMR 7261 CNRS-Universite de Tours. Avenue Monge, Parc Grandmont, Tours 37200, France 
${ }^{4}$ Texas A\&M Agrilife Genomics and Bioinformatics Service, College Station, USA

${ }^{5}$ CEFE, CNRS, Univ Montpellier, Univ Paul Valery Montpellier, EPHE, IRD, Montpellier 34000, France

${ }^{+}$Pierre-Andre Eyer and Alexander J. Blumenfeld should be considered joint first author

\# Edward L. Vargo and Anne-Genevieve Bagneres should be considered joint last authors

*Corresponding author:

Pierre-Andre Eyer

Department of Entomology,

Texas A\&M University,

College Station, 77843, Texas, USA

e-mail: pieyer@live.fr

Keywords: Population genetics, Phylogeography, Social insects, Invasive species, ABC

\begin{abstract}
As native ranges are often geographically structured, invasive species originating from a single source population only carry a fraction of the genetic diversity present in their native range. This invasion pathway is thus often associated with a drastic loss of genetic diversity resulting from a founder event. However, the fraction of diversity brought to the invasive range may vary under different invasion histories, increasing with the size of the propagule, the number of re-introduction events, and/or the total genetic diversity represented by the various source populations in a multiple-introduction scenario. In this study, we generated a SNP dataset for the invasive termiteReticulitermes flavipes from 23 native populations in the eastern United States and six introduced populations throughout the world. Using population genetic analyses and approximate Bayesian computation $(\mathrm{ABC})$, we investigated its worldwide invasion history. We found a complex invasion pathway with multiple events out of the native range and bridgehead introductions from the introduced population in France. Our data suggest that extensive long-distance jump dispersal appears common in both the native and introduced ranges of this species, likely through human transportation. Overall, our results show that similar to multiple introduction events into the invasive range, admixture in the native range prior to invasion can potentially favor invasion success by increasing the genetic diversity that is later transferred to the introduced range.
\end{abstract}

\title{
1 | INTRODUCTION
}

The transport of species beyond their native ranges by human actions is breaking down biogeographical barriers and causing global reorganization of biota (Capinha et al. 2015, van Kleunen et al. 2015), with the ensuing invasions posing a serious threat to biodiversity, agriculture and human health (Simberloff et al. 2013). Successful invaders must disperse into a geographically distant area, establish a viable and fertile population, and spread throughout this new environment, where the biotic and abiotic pressures may differ from those they faced in their native range (Kolar and Lodge 2001). This invasion pathway occurs despite the reduction of genetic diversity that typically follows introductions of invasive species, which is usually associated with inbreeding costs and a loss of adaptive potential. For these reasons, invasions are often seen as paradoxical, since invaders are able to overcome these costs to become ecologically dominant in their novel environment, outcompeting native species adapted to local ecological conditions (Sax and Brown 2000, Facon et al. 2006).

Several life-history traits of invaders may favor them over the course of their invasion. Specific breeding systems, modes of dispersal or physiological characteristics may influence their ability to spread and their establishment success, which thus enhance their colonization rate. Exploring invasion mechanisms relies on unraveling whether these traits differ between introduced and native populations. These differences may result from evolutionary events occurring in the invaded population during the initial phase of introduction 
(Wares et al. 2005), evolving after the introduction due to new ecological pressures (Keller and Taylor 2008), or may already be present within native populations, thereby pre-adapting the source population for invasion success. Therefore, determining the source population of invasive species is critical to conduct comparative studies of life-history traits between introduced and native ranges to understand how they evolved under distinct biotic and abiotic pressures.

Exploring invasion mechanisms also requires assessment of the invasion history, in which a series of demographic events may influence the invasion process and patterns of genetic diversity. A simple invasion history may be the result of a single introduction from the native range; however, an invasive population may also stem from multiple introductions out of the native range, either from the same or different source populations. Similarly, distinct invasive populations may stem from different introduction events from one source population, or from different source populations from the native range. Finally, a successful invasive population itself may become a source for subsequent invasions -a phenomenon coined the 'bridgehead effect'(Lombaert et al. 2010, Bertelsmeier and Keller 2018). Therefore, distinct invasion histories have different outcomes in terms of patterns of genetic diversity and life-history trait evolution. The bottleneck event following an introduction usually results in a loss of genetic diversity in the introduced population (Dlugosch and Parker 2008), but the amount of genetic diversity lost may vary under different invasion histories. The reduction of genetic diversity may be limited when the initial colonizing force is large, when the introduced population is subsequently re-invaded by additional individuals during multiple introduction events, or when the introduced population is invaded by individuals from several genetically distinct source populations (Facon et al. 2006). In rare cases, when there are several introductions from different source populations and these interbreed within an invasive population, genetic diversity may even be higher within this population than its native source populations (Facon et al. 2008). In contrast, the bridgehead effect may result in a severe loss of diversity, as subsequent introductions arise from an already depauperate introduced population. However, the bridgehead effect may promote the spread of phenotypic traits enhancing invasion success in secondary invasive populations, as these traits are already selected for and widespread in the initial introduced population. Investigating patterns of genetic diversity in native and introduced populations can therefore provide information on the invasion history of invasive species.

Reticulitermes flavipes is a subterranean termite species native from Texas to Massachusetts in the eastern USA. The termite has become invasive in localities both near to and distant from the eastern USA. This includes the western USA (Austin et al. 2005, McKern et al. 2006), the Province of Ontario in Canada (Kirby 1965), the Bahamas (Scheffrahn et al. 1999), Chile (Clement et al. 2001) and Uruguay in South America (Austin et al. 2005, Su et al. 2006) and France, Germany, Austria and Italy in western Europe (Kollar 1837, Weidner 1937, Clement et al. 2001, Ghesini et al. 2010). Previous genetic analysis based on microsatellite markers and mtDNA haplotypes have shown that the introduced French population exhibits an average decrease in genetic diversity of $60-80 \%$ compared to native USA populations (Perdereau et al. 2013). The analysis also revealed the occurrence of three main genetic clusters within the native USA range -the 'Eastern cluster' (West Virginia, Virginia, Delaware, North and South Carolina), the 'Gulf Coast cluster' (Florida and Eastern Mississippi-Louisiana) and the 'Southern Louisiana cluster' (the New Orleans and Baton Rouge regions in Louisiana) (Perdereau et al. 2013). Notably, some microsatellite and mtDNA haplotypes found in France were unique to the Southern Louisiana cluster (Perdereau et al. 2013). This finding, together with a similarity in chemical profiles and breeding structures found between France and Louisiana (Perdereau et al. 2010b, Perdereau et al. 2015), suggested that $R$. flavipes was introduced to France from Louisiana, most likely during the 17th and 18th centuries via wood trade between New Orleans and the major French ports on the Atlantic coast (Dronnet et al. 2005, Perdereau et al. 2010a, Perdereau et al. 2013). Although the Louisiana origin of the invasive French population appears well supported, several points remain unclear. First, Perdereau et al. (2019) recently identified a French haplotype more closely related to the 'Eastern cluster' than Louisiana, suggesting multiple native populations from the USA may have invaded France. Additionally, the source(s) of the Canadian and Chilean invasions remain unidentified. Although several populations of $R$. flavipes occur in the Northeastern and Midwestern USA (i.e.,adjacent to Ontario), the only haplotype found in Canada was shared with Louisiana and France (Perdereau et al. 
2013). Therefore, it is unclear whether the Canadian population arose from a primary introduction from Louisiana or from a secondary introduction through France (i.e., bridgehead introduction), as Canada and France share a long common history. Similarly, Chile's unique haplotype was closest to one shared between Louisiana and France (Perdereau et al. 2013), raising the same question regarding primary versus secondary introduction. Overall, these findings suggest a complex invasion history for $R$. flavipes and raise the question of how many native populations may have served as sources of the introduced populations and what the role of bridgeheads might be in the global distribution of this species.

Substantial variability in breeding structure is present among the native USA populations of $R$. flavipes . Most populations are comprised of colonies headed by a monogamous pair of primary (alate-derived) reproductives (simple family). However, some populations are mainly comprised of colonies headed by a few secondary reproductives (i.e., nymph-derived neotenics; extended-family), and other populations comprised of fused colonies (mixed-family colonies) (Vargo and Husseneder 2009, Vargo et al. 2013, Aguero et al. 2020). Interestingly, the French introduced population of $R$. flavipes differs from most native populations, exhibiting a set of 'invasive' traits that enable colonies to form amplified versions of the extended and mixed-family forms. French colonies contain several hundred secondary reproductives and are usually spatially expansive (Dronnet et al. 2005, Vargo and Husseneder 2009, Perdereau et al. 2010a). They display highly similar chemical signatures, which reduces intraspecific antagonism between non-nestmate workers and allows for frequent fusions between colonies (Bagneres et al. 1990, Clement et al. 2001, Perdereau et al. 2010a, Perdereau et al. 2010b). Interestingly, this set of phenotypic traits occurs to a lesser extent in a population from Louisiana (Vargo 2019), which may have enhanced the invasion success of this introduced population in France (Perdereau et al. 2010a, Perdereau et al. 2010c, Perdereau et al. 2015). However, whether this set of traits is common among all introduced populations of $R$. flavipes remains unknown.

Here, we used population genetic analyses and approximate Bayesian computation (ABC) to investigate the invasion history of $R$. flavipes. Using ddRadSeq, we first generated a SNP dataset sequencing 23 native populations in the USA and six introduced populations of this species in France, Germany, Chile, Uruguay, the Bahamas and Canada. We then assessed patterns of genetic structure within the entire native range of the species, and within each of the introduced populations. Finally, in order to elucidate the invasion history of $R$. flavipes, we compared support for different invasion scenarios modeling the number, size, and origin of each introduction event and their admixture using ABC.

\section{2 | MATERIALS AND METHODS}

\section{1 | Population sampling and sequencing}

A total of 268 individuals of $R$. flavipes were collected from 29 populations spanning both native (USA) and different introduced populations in Europe (i.e., France, Germany), North America (Canada and Bahamas) and South America (Chile and Uruguay) (Figure 1; Detailed sampling is provided in Table S1). Samples were stored in $96 \%$ ethanol at 4degC until DNA extraction. Total genomic DNA was extracted from each individual using a modified Gentra Puregene extraction method (Gentra Systems, Inc. Minneapolis, MN, USA). DNA quality and concentration were assessed by agarose gel electrophoresis and Qubit(r) 2.0 Fluorometer (Invitrogen, USA). Suitable genomic DNA was used to construct ddRAD libraries. Libraries were prepared and sequenced at the Texas A\&M AgriLife Genomics and Bioinformatics Service facility using SphI and EcoRI restriction enzymes following the protocol of Peterson et al. (2012). Each sample was identified using a unique indexed barcode. Samples were amplified through PCR with iProof High-Fidelity DNA Polymerase (Bio-Rad). PCR products were purified using AMPure XP beads (Beckman Coulter Inc.). Libraries were size-selected to a range of 300-500 bp using the BluePippin system (Sage Science Inc.). Libraries were sequenced on six flowcell lanes using an Illumina HiSeq 2500 (Illumina Inc., USA) to generate 150 bp paired-end reads.

The paired-end reads were checked for quality control using FastQC v0.11.8 (Andrews 2010). Forward and reverse reads were demultiplexed from their barcodes, assigned to each sample and assembled using Stacks v.2.41 (Rochette et al. 2019). Reads were first aligned to the $R$. flavipes reference genome (Zhou et al. 
unpublished data) using the Burrows-Wheeler Aligner (Li and Durbin 2009). Aligned reads were then run through the reference-based pipeline of Stacks, which built and genotyped the paired-end data, as well as called SNPs using the population-wide data per locus. Only SNPs present in at least $70 \%$ of individuals in half of the populations were kept for downstream analyses. Furthermore, SNPs with mean coverage lower than 5x and higher than 200x were removed using VCFtools v.0.1.15 (Danecek et al. 2011), to prevent unlikely SNPs and highly repetitive regions. Low frequency alleles $(<0.05)$ and highly heterozygous loci $(>$ 0.7) were sorted out, as they likely represent sequencing errors and paralogs (Benestan et al. 2016). The dataset was further converted into input files usable by different downstream software programs through PGDSpider v.2.1.1.5 (Lischer and Excoffier 2011).

\section{2 | Population structure and phylogenetic relationship}

Expected $\left(H_{\mathrm{E}}\right)$ and observed $\left(H_{\mathrm{O}}\right)$ heterozygosity, inbreeding coefficient $\left(F_{I S}\right)$, and population differentiation values $\left(F_{\mathrm{ST}}\right)$ were calculated using Stacks. Population structure among the 23 native and six introduced populations was analyzed using three complementary approaches.

First, the most likely number of genetic clusters (i.e., $\mathrm{K}$ ) in the dataset was estimated, and individuals were assigned into each of them using fastSTRUCTURE v1.040 (Raj et al. 2014). The algorithm ran following an admixture model with allele frequencies correlated and without any geographic a priori about localities. The algorithm was parallelized and automated using Structure_threader (Pina-Martins et al. 2017), and ran for $\mathrm{K}$ ranging from one to 29. The chooseK.pyfunction was used to select the most likely number of genetic clusters. Plots were created by Distruct v2.3 (Chhatre 2019) (available at http://distruct2.popgen.org).

Second, genetic clustering was described using a principal component analysis (PCA) and a discriminant analysis of principal components (DAPC), creating discriminant functions that maximize variance among groups while minimizing variance within groups (Jombart et al. 2010). The most likely number of genetic groups was first inferred by the find.clustersalgorithm on the principal component analysis PCA data, with the Bayesian information criterion utilized to select the number of genetic groups. The optimal number of principal components to inform the DAPC (i.e., maximizing discriminatory power between groups, while preventing overfitting) was then defined using the functionoptim.a.score. Both the PCA and DAPC were performed in $\mathrm{R}$ ( $\mathrm{R}$ Core Team 2020) using the adegenet package (Jombart 2008). Third, population structure was visualized using the relatedness matrix produced by the RADpainter and fineRADstructure software (Malinsky et al. 2018). This method calculates co-ancestry between samples as an independent assessment of population structure. Analyses ran using default parameters of 100,000 burn-in and 100,000 MCMC iterations, and results were visualized in $\mathrm{R}$ through scripts provided with the program (available at http://cichlid.gurdon.cam.ac.uk/fineRAD structure.html).

Phylogenetic relationships among $R$. flavipes individuals were inferred using maximum likelihood (ML) analysis implemented in RAxML v8.2.12 (Stamatakis 2014). In addition, 16 individuals of the sister species $R$. virginicus were used as an outgroup. An acquisition bias correction was applied to the likelihood calculations, removing invariant sites from the alignment through the Phrynomics $\mathrm{R}$ script (available at https://github.com/bbanbury/phrynomics/). The rapid bootstrap analysis and search for the best-scoring maximum likelihood tree was performed using the extended majority rule (MRE)-based bootstopping criterion (Pattengale et al. 2010). Analysis was performed using the GTR $+\mathrm{G}$ nucleotide substitution model.

\subsection{Assessing the invasion history}

The global invasion history of $R$. flavipes was inferred through ABC analyses by comparing support for different invasion scenarios. The scenarios varied according to the origin(s) of introduced populations, the founding population size, the bottleneck duration and the admixture rate if multiple sources were detected. To reduce computational effort, model selection and parameter estimation were performed using the recently developed random forests (RF) machine learning method (ABC RF) available in the abcrf $\mathrm{R}$ package (Pudlo et al. 2015, Raynal et al. 2018). This method requires a reduced number of simulated datasets while providing robust posterior estimates. A step-by-step approach (9 different steps divided into 4 parts; fully explained in Supporting Information 1) was used to infer the different episodes of the invasion history of 
$R$. flavipes, as this type of approach is commonly performed in ABC studies to reduce computational effort (Fraimout et al. 2017, Javal et al. 2019, Ryan et al. 2019). The introduced populations of Germany, Uruguay and the Bahamas were not used in ABC computations as they were represented by too few individuals. Briefly, the first part estimated whether each introduced population (i.e., France, Canada and Chile) arose from independent or bridgehead introduction events (Part A). As this first part indicated that the French population may have played a role in the introduction to Canada and Chile, we first sought to decipher the source(s) of introductions to France alone (Part B). Then, we attempted to identify the sources of the Canada (Part C) and Chile (Part D) populations using France as a potential source. For all scenarios tested, introduction events were followed by a decrease in effective size varying between one to 100 migrants for a duration of zero to 50 years. Posterior distributions of preliminary simulated data sets were used to adjust the range of other priors as wide as possible while retaining biological meaning. For all scenarios in each step, at least 10,000 simulated datasets including all summary statistics implemented in the DIYABC software v.2.1.0 (Cornuet et al. 2014) were generated from 2,000 randomly sampled SNPs. Priors were set uniform for all model parameters and selected based on historical records. The different scenarios tested within each step are provided in the Supplementary Information.

\section{3 | RESULTS}

The 268 samples yielded an average of 7.0 million paired reads per individual (range: $0.03-23.5$ ). Twentynine individuals were removed due to a significant amount of missing data ([?] 60\%) or low coverage ([?] 9.5x). After filtering, the final dataset contained 229 individuals from 29 populations and included 102,144 SNPs on 58,372 polymorphic loci, with an average coverage of $27 \mathrm{x}$ and $32 \%$ missing data.

\section{1 | Population structure}

Strong genetic structure was uncovered among the $R$. flavipesindividuals from fastSTRUCTURE, with K $=4$ best explaining the structure in the data (Fig. 1). At this value of $\mathrm{K}$, most individuals in the dataset $(57.2 \%)$ were clearly assigned to one of the four clusters (assignment probability higher than $99 \%)(73.3 \%$ of individuals were assigned to a unique cluster probability higher than $80 \%$ ). However, the strong genetic structure uncovered among individuals in the native range was inconsistent with their geographic origin, as neighboring samples often exhibited completely different assignment profiles (Fig. 1). In the French introduced range, most samples could be assigned to the same cluster, although some samples from the Paris region had a mixed assignment; a similar mixed assignment was found for the lone German sample. A comparable pattern was observed in the Chilean introduced range, with most samples displaying fixed assignments and only a few with mixed assignments. Although most individuals were assigned to a unique genetic group within each introduced population (France, Chile and Canada), the three introduced populations were separately assigned to three different genetic groups and did not segregate into a single 'introduced' cluster. Because the genetic clustering of the native range did not consistently align with geographic origin, inferring a source population for each introduced population becomes difficult. For example, most samples from Chile were assigned to the same cluster as samples from New York, Wisconsin and Texas. Similarly, although the introduced population in France shared its strongest tie to the native range with Arkansas, France also had ties with Louisiana, Missouri and even one sample in South Carolina. The origin of the samples in Canada was even more complicated, as the genetic cluster present in this population was spread across most native localities.

Similar results to that of fastSTRUCTURE were uncovered using the PCA and DAPC approach (Figure 2). The PCA indicated strong differentiation across $R$. flavipes samples, as they broadly segregated along the two axes. For most localities, genetic clustering was not correlated with geography, as samples from a given locality did not always cluster together. Likewise, no genetic similarity was observed between geographically neighboring localities. Interestingly, such a pattern was also found to a lesser extent in the introduced populations, especially between France and Chile (only a single sample was available from Germany and Uruguay, and just two from the Bahamas). In France, most of the samples segregated together, except for six individuals clustering separately from the rest of the main population. These samples correspond to the individuals from the Paris region exhibiting a mixed fastSTRUCTURE assignment. A similar pattern was 
observed for the samples from Chile, with three samples clustering apart from the main Chilean population. The find.clusters algorithm found the best support for four genetic clusters in the dataset (Figure 2). Notably, the introduced localities of $R$. flavipes did not cluster together; instead, the different introduced populations were spread across the four different DAPC clusters, with some even split between two clusters (Chile and France). Remarkably, a similar pattern was observed from localities within the native range, with samples from a given locality clustering into two (e.g., Texas, Mississippi, Wisconsin) or even three (Louisiana) distinct DAPC clusters.

The co-ancestry matrix highlighted similar patterns when clustering individuals based on their level of relatedness (Figure 3). Using fineRADstructure, all samples from a given locality were not more related to one another than they were to samples from another locality (Figure 3). This result is indicative of an absence of geographic structure in the native range, as most localities were disjunct on the co-ancestry matrix. Notably, the same pattern was observed for the introduced populations, with clustering observed in two (Canada) or three (France and Chile) distinct co-ancestry groups.

\section{2 | Phylogenetic relationship}

ML phylogeny was constructed on 29,875 SNPs after filtering out of invariant sites, using 650 bootstrap replicates, as suggested by the MRE-based bootstopping-criterion. Overall, the tree was consistent with results from the clustering analyses, despite weak bootstrap support throughout the topology (Figure 4). Interestingly, the entire introduced range did not fall out as a single clade; instead, introduced populations arose throughout different branches of the tree. Furthermore, all invasive populations fall out as at least two (Canada and Bahamas) or three different clades (France and Chile). This result also suggests that different introduced populations arose from separate introduction events out of the native range, and that there were several introduction events in most invasive populations.

\section{3 | Invasion history}

The first part of the ABC analysis found that introduced populations in Canada and Chile most likely originated, at least partially, from bridgehead introductions from the previously introduced population in France (Figure 5) (880 cumulative Random Forest (RF) votes), rather than directly from the native range (120 cumulative RF votes) (Supporting Information 1 ).

When analyzing the introduced French population alone in the second part, the first step found that this introduced population could not be unambiguously assigned to a single origin, as all three regions of the native range received a substantial amount of support (East : $449 \mathrm{RF}$ votes, Central : $341 \mathrm{RF}$ votes and Louisiana/Mississippi : $210 \mathrm{RF}$ votes). However, the most likely single introduction event scenario (287 RF votes) was slightly outvoted when compared against a two-population admixture scenario (314 RF votes, second step), which was itself outvoted by scenarios simulating the French origin through admixture of all three native regions ( 754 cumulative $\mathrm{RF}$ votes, third step). The fourth step of the second part (native range was further divided) found that Georgia and South Carolina (197 RF votes) obtained the highest support for an origin of the French population. However, Louisiana (167 RF votes), and Alabama and Mississippi (161 $\mathrm{RF}$ votes) also received a substantial number of votes, while other source populations obtained a significant number of RF votes (i.e.,Maryland and New York: 94 RF votes; Tennessee and North Carolina: 83 RF votes; Florida: $74 \mathrm{RF}$ votes). Overall, these findings suggest the occurrence of multiple introduction events out of the native range. However, at both large (step1) and finer scale (step4), no scenario received a majority vote, preventing a definitive determination of the source population of the introduced population in France.

The third part aimed at analyzing the origins of the Canadian introduced population, using the French introduced population as a potential source. $\mathrm{ABC}$ analyses revealed that the most probable scenario for the origin of the Canadian population was an introduction from a French bridgehead and its admixture with a separate introduction event from the native range ( $463 \mathrm{RF}$ votes), rather than entirely from the native range (240 RF votes) or French bridgehead (297 RF votes). When the native range was further divided, ABC analyses found that the additional introduction event that admixed with the French bridgehead in Canada likely originated from the surrounding regions (i.e., Maryland and New York: 132 RF votes; Ohio, Kentucky, 
Indiana and Illinois: $122 \mathrm{RF}$ votes; Wisconsin: $120 \mathrm{RF}$ votes). A similar invasion history was identified for Chile, as a bridgehead from France combined with an additional introduction event from the native range was found most likely (542 RF votes), rather than entirely from the native range (138 RF votes) or French bridgehead (320 RF votes). When the native range was further divided, ABC revealed that the additional introduction event likely originated from Wisconsin (182 RF votes).

Overall, the parameter estimation consistently suggested the origin of the introduced French population 200 to 271 years ago, which resulted from the arrival of 54 to 62 migrants (Figure 5). This population was suggested to have experienced a bottleneck for a duration of 8 to 8.5 years. The introduced population in Canada was estimated to originate 101 years ago, and experienced a short bottleneck of 3.5 years. This population arose from an initial propagule of between 47 to 59 migrants, $64 \%$ of them coming from a bridgehead from France and 36\% from the surrounding localities in the native range. The introduction to Chile was estimated to have occurred around 93 years ago, following a short bottleneck of 3.5 years. This population resulted from the arrival of 46 to 51 migrants, half of them coming from France (52\%) and the other from an additional introduction event from the native range, probably Wisconsin. All other posterior probabilities, RF votes and posterior parameter estimates are available in the Supplementary Information.

\section{4 | DISCUSSION}

Our study provides insights into the invasion pathway of the termiteReticulitermes flavipes, highlighting numerous and recent human-mediated jump dispersals in both the native and introduced range of this species. We first revealed a strong clustering among individuals within the native range of this species in the eastern USA. Yet, these individual differences were not due to geography, as highly different individuals were found in the same locality and highly similar ones in localities separated by several thousand kilometers. This finding indicates extensive movement of colonies throughout the native range, likely through human transportation. We also highlight a complex invasion history with multiple events out of the native range and bridgehead introductions from the introduced population in France. The apparent genetic shuffling within the native range limits our ability to assign an exact source population(s) for the different introduced ranges. However, similar to the effect of multiple introductions into the invasive range, admixture in the native range prior to invasion can potentially favor invasion success by increasing the genetic diversity later conveyed to the introduced ranges.

Our findings revealed the occurrence of multiple introductions from different native localities serving as sources for the invasive ranges of France, Chile and Canada. Additionally, Canada and Chile received secondary invasions from the introduced population in France, which acted as a bridgehead. Some previous results indicated there may have been several introductions into France (Perdereau et al. 2019). Reticulitermes flavipes was first reported in Austria in 1837; however, it probably occurred earlier in Western Europe, when it was identified as $R$. santonensis (Kollar 1837). Despite being unable to definitively link its source population(s) to the New Orleans region as previously suggested (Perdereau et al. 2013, 2015), our data, based on a larger sample size and more informative markers, do not rule out this possibility, suggesting that this invasive population originated from somewhere in the southeastern USA, from Louisiana to South Carolina. However, it is possible that the French population originated from colonies originally coming from the New Orleans region that had been transported elsewhere within the native range, such as South Carolina. Such long-distance jump dispersal within the native range necessarily hampers clear identification of the source population(s). Likewise, although our results suggest that the Canadian and Chilean introduced populations originated from admixture between the introduced population of France and native localities in the northern range of $R$. flavipes, these results suffer from low confidence, potentially due to genetic mixing between native localities. Overall, these findings indicate that jump dispersal may not be restricted to a single region within the native range of this species. Instead, such dispersal appears common with $R$. flavipes , suggesting that the evolutionary mechanisms promoting this phenomenon are globally distributed across the species distribution range.

The genetic patterns observed in $R$. flavipes may be explained by numerous and recent jump dispersal events across the native range, likely mediated via human trade and transportation. This finding exemplifies 
species spread by stratified dispersal, whereby individuals disperse at different spatial scales, from local to long-distance movement (Shigesada et al. 1995). Local scale dispersal relies on the biological dispersal ability of the species, ranging from limited (i.e., budding) to moderate dispersal (i.e., nuptial flight). In contrast, long-distance dispersal is often human-mediated and therefore considered stochastic and difficult to determine. Notably, our study revealed both 1) genetically distinct individuals inhabiting the same locality and 2) genetically similar individuals separated by several thousand kilometers. The geographic distance separating highly similar individuals far exceeds the biological dispersal ability of this species, suggesting these individuals were artificially transported to a different locality. Additionally, the finding of genetically distinct individuals within the same or adjacent localities indicates a low level of mixing between those individuals. This may stem from reduced local dispersal, by which transported individuals interbreed and do not disperse far from their landing point. A high proportion of new reproductives of $R$. flavipes do in fact interbreed with their nestmates during mating flights $(25 \%)$; however, the proportion of inbred successful founders is significantly reduced among established colonies (DeHeer and Vargo 2006). Therefore, this inbreeding depression may select against the interbreeding of artificially transported colonies. Also, $R$. flavipes usually disperse through nuptial flights, which should enhance gene flow over large scales (Vargo 2003). Consequently, a scenario by which transported individuals interbreed and do not disperse far from their landing point may not alone explain the pattern observed in this study. The finding of highly genetically different individuals within the same locality suggests that some of the long-distance jump dispersal events are probably too recent to allow transported individuals to admix with local colonies to homogenize the gene pool within populations.

The global spread of invasive species is strongly influenced by long-distance jump dispersal, even once established within an introduced range (Suarez et al. 2001). These long-distance jump dispersal events are more effective, and often required, for rapidly reaching widespread distributions. The worldwide distribution of the Argentine ant has been shown to primarily stem from human-mediated jump dispersal, rather than from its classical spread through colony budding, as the latter would have to be three orders of magnitude higher to explain its actual distribution (Suarez et al. 2001). This finding is also exemplified in the global distribution of the red imported fire antSolenopsis invicta, which utilized long-range jump dispersal to first invade the southeastern US, and subsequently Asia and Australia from its bridgehead in the USA (Ascunce et al. 2011). In general, eusocial organisms like ants (Bertelsmeier et al. 2018) and termites (Buczkowski and Bertelsmeier 2017, Blumenfeld and Vargo 2020) appear adept at utilizing human-mediated jump dispersal to broaden their global distributions. These serial long-distance movements are also observed among regions within invasive ranges, across a wide variety of taxa, such as the aforementioned $S$. invicta throughout the southern USA (Lofgren 1986) and China (Ascunce et al. 2011), the western mosquitofish Gambusia affinis in New Zealand (Purcell and Stockwell 2015), and plants in China (Horvitz et al. 2017). Although most studies demonstrate the importance of human-mediated dispersal in shaping invasion dynamics following establishment, it often remains unclear whether long-distance jump dispersal pre-exists in the native range of invasive species, and its relative importance in the pattern of genetic diversity observed at the global scale of these species.

Native ranges of many invasive species often remain geographically structured (Voisin et al. 2005, Beck et al. 2008, Leinonen et al. 2008, Verhoeven et al. 2011). For example, native populations of S. invicta are strongly geographically differentiated (Ross et al. 2007). Though rare long-distance dispersals have been reported (Ahrens et al. 2005), these events occurred far in the past and have been attributed to strong winds during nuptial flights or the rafting of entire colonies during flooding events (Holldobler and Wilson 1990), rather than from human-mediated transport (Ahrens et al. 2005). Native populations of another termite invader Coptotermes formosanus in China are highly structured, with distinct native populations representing different genetic clusters (Blumenfeld et al. 2020). This structuring suggests reduced gene flow across populations, and therefore a limited number of human-mediated dispersal events within the native range of this species. Our results stand in sharp contrast with the strong population structure commonly uncovered within the native ranges of invasive species, as frequent jump dispersal appears to have occurred in the native range of $R$. flavipes. Understanding the factors driving the differences between these two 
invasive termite species may shed light on key evolutionary mechanisms underlying their invasion success. Furthermore, while most studies focus on unraveling invasion pathways out of a native range, our results stress the need to consider evolutionary processes and human-mediated dispersal that may already be present within the native range of an invasive species, as these can affect the level and distribution of genetic diversity in both the native and invasive ranges.

Extensive human-mediated jump dispersal has been reported in the native range of a few species. For example, in the invasive tree Acacia pycnantha, extensive transport and replanting throughout its native Australian range prior to its introduction to South Africa resulted in highly admixed genotypes already present in the native range. This feature has consequently prevented an accurate identification of the native source population(s), as highly admixed genotypes and comparable genetic diversity were present in both ranges of the species (Le Roux et al. 2013). A similar pattern has been found in the North American rangeland weed, Centaurea diffusa, where an extremely low level of population structure in the native range hindered the assignment of its introduced population to its likely native source location (Marrs et al. 2008). However, the genetic patterns observed in these studies are slightly different than the one observed in $R$. flavipes, as the inability to pinpoint the origins of invasive populations stems from the near-panmixia found across the native range. Therefore, the patterns in these other species most likely stem from an ancient and continuous genetic shuffling throughout the native range. In contrast, the lack of geographic structure despite highly genetically different individuals indicates recent and stochastic long-distance dispersal in $R$. flavipes .

The invasion success of termites is tightly linked with their ability to eat wood, nest in wood and cultivated plants and readily generate secondary reproductives, as all 28 species of invasive termites share these three traits (Evans et al. 2013). These traits are common in lower termites like $R$. flavipes and $C$. formosanus, and ensure that any piece of wood serving as a nest or foraging site has the potential to become a viable propagule (Evans et al. 2010, Evans et al. 2013). Although these traits may enhance the frequency of human-mediated dispersal in $R$. flavipes, their occurrence in both species cannot explain the difference in long-distance dispersal in the native ranges of these two species. In $R$. flavipes, repeated human-mediated dispersal could reflect a higher degree of propagule pressure from different USA regions, representing multiple hubs of intense human activity and timber production. Forests and timber production are unequally distributed across the eastern USA (Brown et al. 1999, Howard and Liang 2019), and may therefore require significant wood transportation throughout this part of the country from high to low timber-producing regions. Similarly, the frequency of human-mediated dispersal may reflect the connectivity between native regions. In the introduced population of $R$. flavipes in France, the distribution of genetic diversity is associated with the railway network, highlighting its possible role in displacing termites over long distances (Andrieu et al. 2017, Suppo et al. 2018, Perdereau et al. 2019). In the USA, about 14,000km of track were active by 1850 , mainly in the eastern USA $(141,000 \mathrm{~km}$ in 1880 and over 400,000km in 1916) (United States Census Bureau 1890, Chandler 1965). In contrast, the first $10 \mathrm{~km}$ railway was built in China in 1881 , but less than $13,000 \mathrm{~km}$ were in use by 1948 for the whole country. This difference in connectivity may explain the numerous longdistance dispersal events in the native range of $R$. flavipes and their absence in the Chinese native range of $C$. formosanus. Interestingly, the railroad network in the USA has also been suggested to represent a major dispersal mode for C. formosanus in its invasive range in this country (Austin et al. 2008). Overall, many invasive social insect species originate from South America or East Asia (Tsutsui et al. 2000, Heller 2004, Ross et al. 2007, Eyer et al. 2018a, Eyer et al. 2018b, Eyer et al. 2020). The population structure observed in most native populations may simply reflect the reduced connectivity between native regions in these areas, potentially resulting from a lack of internal trade among regions or difficulty in reaching isolated geographic areas. Our findings in $R$. flavipesmay shed light on frequent long-distance dispersal already present within native ranges of invasive species, especially those originating from regions with a long history of dense transport networks.

While the invasion scenario of numerous introductions from distinct source populations and their admixture in the invasive range may explain the levels of admixture observed in the introduced populations of France and Chile, we cannot rule out the possibility that admixed introduced populations re-invaded the native 
range of $R$. flavipes.Similarly, it is possible that populations were already admixed before propagules were transported worldwide. Native populations of many invasive species often remain geographically isolated and locally adapted. It has been suggested that a temporary loss of local adaptation in recent invaders fundamentally alters the fitness consequences of admixture (Verhoeven et al. 2011). Long-distance dispersal in the native range enhances gene flow between distant populations that are otherwise isolated. Similar to post-introduction increases of genetic diversity through multiple introduction events (Kolbe et al. 2004, Stenoien et al. 2005, Garcia et al. 2017), admixture between native populations prior to an introduction event may enhance the amount of genetic diversity brought to the invasive range. Admixture may improve invasion success through recombination between distinct genotypes, potentially creating novel combinations of traits, and/or increasing the level of genetic diversity upon which natural selection can act. Pre- or post-introduction admixture may also reduce the inbreeding load by reducing the expression of recessive deleterious alleles or lead to heterosis effects, potentially improving the establishment and early success of invasive species (Ellstrand and Schierenbeck 2000, Drake 2006, Keller and Taylor 2008, Hahn and Rieseberg 2016). Overall, increased genetic diversity via admixture may favor subsequent introductions given the novel selection pressures invasive species face in their new environments (Verhoeven et al. 2011).

\section{Conclusion}

In this study, we describe the occurrence of long-distance jump dispersal in the native range of the termite $R$. flavipes . This long-distance dispersal may allow admixture between populations that are otherwise isolated. Similar to multiple introductions through different pathways, admixture in native populations prior to introduction may favor invasion success by increasing the amount of genetic diversity brought to the introduced range. However, pre-introduction admixture may not be as common as multiple introduction scenarios (i.e.,post-introduction admixture), because the benefits of admixture in the novel environment of the invasive range are probably higher, and the costs smaller. As native populations are locally adapted, long-distance dispersal and admixture therefore disturb this local adaptation (Verhoeven et al. 2011, Palacio-Lopez et al. 2017). In contrast, populations in invaded ranges are too recent to be locally adapted. This lack of local adaptation releases introduced populations from maintaining specific locale-selected allelic combinations, and therefore allows them to fully benefit from admixture.

\section{Acknowledgements}

We wish to thank Renato Ripa (Instituto de Investigaciones Agropecuarias, Chile), Ariel Camousseight (National History Museum of Science from Santiago, Chile), James Austin (BASF, Research Triangle Park, NC, USA), Uwe Noldt (Germany) and Guillaume Baudouin (Paris City Hall, France) for giving us samples. This work was supported by USDA-NRICGP grants to ELV (00-35302-9377 and 2002-35352-12490), the Urban Entomology Endowment at Texas A\&M University and CNRS grants and contracts to AGB.

\section{Data accessibility}

The data reported in this study will be deposited in the Open Science Framework database upon acceptance, https://osf.io (DOI XXX).

\section{Author contributions}

ELV and AGB designed the study. EP, SD, FD, AGB and ELV collected the data. LNLJ performed the molecular analyses. AJB, PAE, LNLJ and PTS analyzed the data. PAE and AJB wrote the paper with contributions of ELV.

\section{SUPPLEMENTARY MATERIAL}

Additional material may be found in the online version of this article.

Table S1: Sampling information for every individual used in this study.

Supplementary information 1 : A detailed description of the step-by-step ABC RF analysis is covered, including: 1) priors used for the analyses, 2) graphical representation and random forest votes for each 
scenario within each step, 3) an overall PCA of the simulated datasets for every scenario for each step and 4) parameter estimates for the final invasion model.

\section{FIGURE LEGENDS}

Figure 1 : fastSTRUCTURE assignment for each individual of $R$. flavipes for $\mathrm{K}=4$. Each vertical bar represents an individual and each color represents a distinct genetic cluster. Individual fastSTRUCTURE assignments are geographically located in the native and introduced ranges of $R$. flavipes .

Figure 2 : Principal Component Analysis (PCA) ofReticulitermes flavipes individuals. Individuals are grouped according the Discriminant Analysis of Principal Components (DAPC) with best support for K = 4 genetic clusters.

Figure 3 : Co-ancestry matrix between each pair of individuals inferred using fineRADstructure. Each pixel represents a pair of individuals. Co-ancestry coefficients between two individuals are designated on a color spectrum. Low values are shown in yellow; higher values are shown in darker colors.

Figure 4 : Maximum likelihood phylogenetic tree ofReticulitermes flavipes individuals from RAxML. Individuals are colored according to their fastSTRUCTURE assignments $(K=4)$. Samples from the introduced ranges are highlighted with an emphasized tip. The phylogenetic tree is rooted with $10 R$. virginicus samples.

Figure 5 : Graphical representation of the invasion pathway ofReticulitermes flavipes out of eastern USA inferred through ABC RF in France, Canada and Chile. For each introduction event out of the native range, the insets represent the most likely native source populations. All scenarios tested and results for each ABC step, as well as all of the posterior parameter estimates, are provided in the Supplementary Information.

\section{REFERENCES}

Aguero, C., P. A. Eyer, and E. L. Vargo. 2020. Increased genetic diversity from colony merging in termites does not improve survival against a fungal pathogen. Scientific Reports10 :4212.

Ahrens, M. E., K. G. Ross, and D. D. Shoemaker. 2005. Phylogeographic structure of the fire antSolenopsis Invicta in its native South American range: roles of natural barriers and habitat connectivity. Evolution59 :1733-1743.

Andrews, S. 2010. FastQC: a quality control tool for high throughput sequence data. Babraham Bioinformatics, Babraham Institute, Cambridge, United Kingdom.

Andrieu, D., E. Perdereau, C. Robinet, C. Suppo, S. Dupont, and A. Bagneres. 2017. Geographie des termites souterrains en region Centre-Val de Loire: Les risques apportes par une espece invasive. Cybergeo: European Journal of Geography, Environnement, Nature, Paysage 852 :0-1.

Ascunce, M. S., C.-C. Yang, J. Oakey, L. Calcaterra, W.-J. Wu, C.-J. Shih, J. Goudet, K. G. Ross, and D. Shoemaker. 2011. Global invasion history of the fire antSolenopsis invicta. Science 331 :1066-1068.

Austin, J. W., G. J. Glenn, and R. E. Gold. 2008. Protecting urban infrastructure from Formosan termite (Isoptera: Rhinotermitidae) attack: a case study for United States railroads. Sociobiology 51 :231-247.

Austin, J. W., A. L. Szalanski, R. H. Scheffrahn, and M. T. Messenger. 2005. Genetic variation ofReticulitermes flavipes (Isoptera: Rhinotermitidae) in North America applying the mitochondrial rRNA 16S gene. Annals of the Entomological Society of America $98: 980-988$.

Bagneres, A. G., J. L. Clement, M. S. Blum, R. F. Severson, C. Joulie, and C. Lange. 1990. Cuticular hydrocarbons and defensive compounds of Reticulitermes flavipes(Kollar) and R. santonensis (Feytaud): polymorphism and chemotaxonomy. Journal of Chemical Ecology 16 :3213-3244.

Beck, J. B., H. Schmuths, and B. A. Schaal. 2008. Native range genetic variation in Arabidopsis thaliana is strongly geographically structured and reflects Pleistocene glacial dynamics. Molecular ecology 17 :902-915. 
Benestan, L. M., A.-L. Ferchaud, P. A. Hohenlohe, B. A. Garner, G. J. P. Naylor, I. B. Baums, M. K. Schwartz, J. L. Kelley, and G. Luikart. 2016. Conservation genomics of natural and managed populations: building a conceptual and practical framework. Molecular Ecology 25 :2967-2977.

Bertelsmeier, C. and L. Keller. 2018. Bridgehead effects and role of adaptive evolution in invasive populations. Trends in Ecology \& Evolution 33 :527-534.

Bertelsmeier, C., S. Ollier, A. M. Liebhold, E. G. Brockerhoff, D. Ward, and L. Keller. 2018. Recurrent bridgehead effects accelerate global alien ant spread. Proceedings of the National Academy of Sciences, USA $115: 5486$.

Blumenfeld, A. J. and E. L. Vargo. 2020. Geography, opportunity and bridgeheads facilitate termite invasions to the United States. Biological Invasions.

Brown, S. L., P. Schroeder, and J. S. Kern. 1999. Spatial distribution of biomass in forests of the eastern USA. Forest Ecology and Management $123: 81-90$.

Buczkowski, G. and C. Bertelsmeier. 2017. Invasive termites in a changing climate: A global perspective. Ecology and Evolution 7 :974-985.

Capinha, C., F. Essl, H. Seebens, D. Moser, and H. M. Pereira. 2015. The dispersal of alien species redefines biogeography in the Anthropocene. Science $348: 1248$.

Chandler, A. D. J. 1965. The Railroads: Pioneers in Modern Corporate Management. Business History Review 39 :16-40.

Chhatre, V. E. 2019. Distruct v2.3, a modified cluster membership plotting script.

Clement, J. L., A. G. Bagneres, P. Uva, L. Wilfert, A. Quintana, J. Reinhardt, and S. Dronnet. 2001. Biosystematics of Reticulitermes termites in Europe: morphological, chemical and molecular data. Insectes Sociaux408:202-215.

Cornuet, J.-M., P. Pudlo, J. Veyssier, A. Dehne-Garcia, M. Gautier, R. Leblois, J.-M. Marin, and A. Estoup. 2014. DIYABC v2.0: a software to make approximate Bayesian computation inferences about population history using single nucleotide polymorphism, DNA sequence and microsatellite data. Bioinformatics30 :1187-1189.

Danecek, P., A. Auton, G. Abecasis, C. A. Albers, E. Banks, M. A. DePristo, R. E. Handsaker, G. Lunter, G. T. Marth, S. T. Sherry, G. McVean, R. Durbin, and G. Genomes Project Analysis. 2011. The variant call format and VCFtools. Bioinformatics27:2156-2158.

DeHeer, C. J. and E. L. Vargo. 2006. An indirect test of inbreeding depression in the termites Reticulitermes flavipes and Reticulitermes virginicus. Behavioral Ecology and Sociobiology 59 :753-761.

Dlugosch, K. M. and I. M. Parker. 2008. Founding events in species invasions: genetic variation, adaptive evolution, and the role of multiple introductions. Molecular ecology $17: 431-449$.

Drake, J. M. 2006. Heterosis, the catapult effect and establishment success of a colonizing bird. Biology Letters $2: 304-307$.

Dronnet, S., M. Chapuisat, E. L. Vargo, C. Lohou, and A.-G. Bagneres. 2005. Genetic analysis of the breeding system of an invasive subterranean termite, Reticulitermes santonensis, in urban and natural habitats. Molecular ecology 14 :1311-1320.

Ellstrand, N. C. and K. A. Schierenbeck. 2000. Hybridization as a stimulus for the evolution of invasiveness in plants? Proceedings of the National Academy of Sciences, USA 97 :7043-7050.

Evans, T. A., B. T. Forschler, and J. K. Grace. 2013. Biology of invasive termites: a worldwide review. Annual Review of Entomology $58: 455-474$. 
Evans, T. A., R. Inta, and J. C. S. Lai. 2010. Foraging choice and replacement reproductives facilitate invasiveness in drywood termites. Biological Invasions13 :1579-1587.

Eyer, P.-A., K. Matsuura, E. L. Vargo, K. Kobayashi, T. Yashiro, W. Suehiro, C. Himuro, T. Yokoi, B. Guenard, R. R. Dunn, and K. Tsuji. 2018a. Inbreeding tolerance as a pre-adapted trait for invasion success in the invasive antBrachyponera chinensis. Molecular ecology $27: 4711-4724$.

Eyer, P.-A., B. McDowell, L. N. L. Johnson, L. A. Calcaterra, M. B. Fernandez, D. Shoemaker, R. T. Puckett, and E. L. Vargo. 2018b. Supercolonial structure of invasive populations of the tawny crazy ant Nylanderia fulva in the US. BMC evolutionary biology $18: 209$.

Eyer, P. A., E. M. Espinoza, A. J. Blumenfeld, and E. L. Vargo. 2020. The underdog invader: Breeding system and colony genetic structure of the dark rover ant (Brachymyrmex patagonicus Mayr). Ecology and Evolution 10 :493-505.

Facon, B., B. J. Genton, J. Shykoff, P. Jarne, A. Estoup, and P. David. 2006. A general eco-evolutionary framework for understanding bioinvasions. Trends in Ecology \& Evolution 21 :130-135.

Facon, B., J.-P. Pointier, P. Jarne, V. Sarda, and P. David. 2008. High Genetic Variance in Life-History Strategies within Invasive Populations by Way of Multiple Introductions. Current Biology 18 :363-367.

Fraimout, A., V. Debat, S. Fellous, R. A. Hufbauer, J. Foucaud, P. Pudlo, J.-M. Marin, D. K. Price, J. Cattel, X. Chen, M. Depra, P. Francois Duyck, C. Guedot, M. Kenis, M. T. Kimura, G. Loeb, A. Loiseau, I. Martinez-Sanudo, M. Pascual, M. Polihronakis Richmond, P. Shearer, N. Singh, K. Tamura, A. Xuereb, J. Zhang, and A. Estoup. 2017. Deciphering the routes of invasion ofDrosophila suzukii by means of ABC random forest. Molecular Biology and Evolution 34 :980-996.

Garcia, K., Y. Melero, S. Palazon, J. Gosalbez, and J. Castresana. 2017. Spatial mixing of mitochondrial lineages and greater genetic diversity in some invasive populations of the American mink (Neovison vison) compared to native populations. Biological Invasions 19 :2663-2673.

Ghesini, S., M. T. Messenger, N. Pilon, and M. Marini. 2010. First Report of Reticulitermes flavipes (Isoptera: Rhinotermitidae) in Italy. Florida Entomologist93 :327-328, 322.

Hahn, M. A. and L. H. Rieseberg. 2016. Genetic admixture and heterosis may enhance the invasiveness of common ragweed. Evolutionary Applications 10 :241-250.

Heller, N. E. 2004. Colony structure in introduced and native populations of the invasive Argentine ant,Linepithema humile. Insectes Sociaux $51: 378-386$.

Holldobler, B. and E. O. Wilson. 1990. The Ants. The Belknap Press of Harvard University, Cambridge, Mass.

Horvitz, N., R. Wang, F.-H. Wan, and R. Nathan. 2017. Pervasive human-mediated large-scale invasion: analysis of spread patterns and their underlying mechanisms in 17 of China's worst invasive plants. Journal of Ecology 105 :85-94.

Howard, J. L. and S. Liang. 2019. US timber production, trade, consumption, and price statistics, 1965-2017.

Javal, M., E. Lombaert, T. Tsykun, C. Courtin, C. Kerdelhue, S. Prospero, A. Roques, and G. Roux. 2019. Deciphering the worldwide invasion of the Asian long-horned beetle: A recurrent invasion process from the native area together with a bridgehead effect. Mol. Ecol. 28 :951-967.

Jombart, T. 2008. adegenet: a R package for the multivariate analysis of genetic markers. Bioinformatics 24 :1403-1405.

Jombart, T., S. Devillard, and F. Balloux. 2010. Discriminant analysis of principal components: a new method for the analysis of genetically structured populations. BMC Genetics 11 :94. 
Keller, S. R. and D. R. Taylor. 2008. History, chance and adaptation during biological invasion: separating stochastic phenotypic evolution from response to selection. Ecology Letters 11 :852-866.

Kirby, C. S. 1965. The distribution of termites in Ontario after 25 Years. The Canadian Entomologist97 :310-314.

Kolar, C. S. and D. M. Lodge. 2001. Progress in invasion biology: predicting invaders. Trends in Ecology \& Evolution 16 :199-204.

Kolbe, J. J., R. E. Glor, L. Rodriguez Schettino, A. C. Lara, A. Larson, and J. B. Losos. 2004. Genetic variation increases during biological invasion by a Cuban lizard. Nature 431 :177.

Kollar, V. 1837. Naturgeschichte des scheadlichen Insekten. Verb Landwirtsch Ges Wien 5 :411-413.

Le Roux, J. J., D. M. Richardson, J. R. U. Wilson, and J. Ndlovu. 2013. Human usage in the native range may determine future genetic structure of an invasion: insights fromAcacia pycnantha. BMC Ecology 13 $: 37$.

Leinonen, T., R. B. O'Hara, J. M. Cano, and J. Merila. 2008. Comparative studies of quantitative trait and neutral marker divergence: a meta-analysis. Journal of Evolutionary Biology 21 :1-17.

Li, H. and R. Durbin. 2009. Fast and accurate short read alignment with Burrows-Wheeler transform. Bioinformatics 25 :1754-1760.

Lischer, H. E. L. and L. Excoffier. 2011. PGDSpider: an automated data conversion tool for connecting population genetics and genomics programs. Bioinformatics28 :298-299.

Lofgren, C. S. 1986. History of imported fire ants in the United States. Pages 36-49 in C. S. Lofgren and R. K. Vander Meer, editors. Fire ants and leaf cutting ants: biology and management. Westview Press, Boulder, CO, USA.

Lombaert, E., T. Guillemaud, J.-M. Cornuet, T. Malausa, B. Facon, and A. Estoup. 2010. Bridgehead Effect in the Worldwide Invasion of the Biocontrol Harlequin Ladybird. PLoS ONE5 :e9743.

Malinsky, M., E. Trucchi, D. J. Lawson, and D. Falush. 2018. RADpainter and fineRADstructure: population inference from RADseq data. Molecular Biology and Evolution35 :1284-1290.

Marrs, R. A., R. Sforza, and R. A. Hufbauer. 2008. When invasion increases population genetic structure: a study with Centaurea diffusa. Biological Invasions10 :561-572.

McKern, J. A., A. L. Szalanski, and J. W. Austin. 2006. First record of Reticulitermes flavipes and Reticulitermes hageni in Oregon (Isoptera: Rhinotermitidae). Florida Entomologist 89 :541-542, 542.

Palacio-Lopez, K., S. R. Keller, and J. Molofsky. 2017. Genomic Admixture Between Locally Adapted Populations of Arabidopsis thaliana (mouse ear cress): Evidence of Optimal Genetic Outcrossing Distance. Journal of Heredity $109: 38-46$.

Pattengale, N. D., M. Alipour, O. R. P. Bininda-Emonds, B. M. E. Moret, and A. Stamatkis. 2010. How many bootstrap replicates are necessary? Journal of Computational Biology17 :337-354.

Perdereau, E., A. G. Bagneres, S. Bankhead-Dronnet, S. Dupont, M. Zimmermann, E. L. Vargo, and F. Dedeine. 2013. Global genetic analysis reveals the putative native source of the invasive termite, Reticulitermes flavipes, in France. Molecular ecology22 :1105-1119.

Perdereau, E., A. G. Bagneres, S. Dupont, and F. Dedeine. 2010a. High occurrence of colony fusion in a European population of the American termite Reticulitermes flavipes . Insectes Sociaux 57 :393-402.

Perdereau, E., A. G. Bagneres, E. L. Vargo, G. Baudouin, Y. Xu, P. Labadie, S. Dupont, and F. Dedeine. 2015. Relationship between invasion success and colony breeding structure in a subterranean termite. Molecular ecology $24: 2125-2142$. 
Perdereau, E., G. Baudouin, S. Bankhead-Dronnet, Z. Chevalier, M. Zimmermann, S. Dupont, F. Dedeine, and A.-G. Bagneres. 2019. Invasion dynamics of a termite, Reticulitermes flavipes, at different spatial scales in France. Insects $10: 30$.

Perdereau, E., F. Dedeine, J.-P. Christides, and A.-G. Bagneres. 2010b. Variations in Worker Cuticular Hydrocarbons and Soldier Isoprenoid Defensive Secretions Within and Among Introduced and Native Populations of the Subterranean Termite, Reticulitermes flavipes. Journal of Chemical Ecology36 :1189-1198.

Perdereau, E., F. Dedeine, J. P. Christides, S. Dupont, and A. G. Bagneres. 2010c. Competition between invasive and indigenous species: an insular case study of subterranean termites. Biological Invasions 13 $: 1457-1470$.

Peterson, B. K., J. N. Weber, E. H. Kay, H. S. Fisher, and H. E. Hoekstra. 2012. Double digest RADseq: An inexpensive method for de novo SNP discovery and genotyping in model and non-model species. PLoS ONE 7 :e37135.

Pina-Martins, F., D. N. Silva, J. Fino, and O. S. Paulo. 2017. Structure_threader: An improved method for automation and parallelization of programs structure, fastStructure and MavericK on multicore CPU systems. Molecular Ecology Resources17 :e268-e274.

Pudlo, P., J.-M. Marin, A. Estoup, J.-M. Cornuet, M. Gautier, and C. P. Robert. 2015. Reliable ABC model choice via random forests. Bioinformatics $32: 859-866$.

Purcell, K. M. and C. A. Stockwell. 2015. An evaluation of the genetic structure and post-introduction dispersal of a non-native invasive fish to the North Island of New Zealand. Biological Invasions 17 :625-636.

R Core Team. 2020. R: A language and environment for statistical computing. R Foundation for Statistical Computing, Vienna, Austria.

Raj, A., M. Stephens, and J. K. Pritchard. 2014. fastSTRUCTURE: variational inference of population structure in large SNP data sets. Genetics $197: 573-589$.

Raynal, L., J.-M. Marin, P. Pudlo, M. Ribatet, C. P. Robert, and A. Estoup. 2018. ABC random forests for Bayesian parameter inference. Bioinformatics 35 :1720-1728.

Rochette, N. C., A. G. Rivera-Colon, and J. M. Catchen. 2019. Stacks 2: analytical methods for paired-end sequencing improve RADseq-based population genomics. Molecular Ecology 28 :4737-4754.

Ross, K. G., M. J. B. Krieger, L. Keller, and D. D. Shoemaker. 2007. Genetic variation and structure in native populations of the fire ant Solenopsis invicta : evolutionary and demographic implications. Biological Journal of the Linnean Society $92: 541-560$.

Ryan, S. F., E. Lombaert, A. Espeset, R. Vila, G. Talavera, V. Dincă, M. M. Doellman, M. A. Renshaw, M. W. Eng, E. A. Hornett, Y. Li, M. E. Pfrender, and D. Shoemaker. 2019. Global invasion history of the agricultural pest butterfly Pieris rapae revealed with genomics and citizen science. Proceedings of the National Academy of Sciences, USA $116: 20015$.

Sax, D. F. and J. H. Brown. 2000. The paradox of invasion. Global Ecology and Biogeography 9 :363-371.

Scheffrahn, R. H., J. A. Chase, J. R. Mangold, J. Krĕcĕk, and N.-Y. Su. 1999. First Record ofReticulitermes (Isoptera: Rhinotermitidae) from the West Indies:R. flavipes on Grand Bahama Island. The Florida Entomologist $82: 480-482$.

Shigesada, N., K. Kawasaki, and Y. Takeda. 1995. Modeling stratified diffusion in biological invasions. The American Naturalist $146: 229-251$.

Simberloff, D., J.-L. Martin, P. Genovesi, V. Maris, D. A. Wardle, J. Aronson, F. Courchamp, B. Galil, E. García-Berthou, M. Pascal, P. Pyšek, R. Sousa, E. Tabacchi, and M. Vilà. 2013. Impacts of biological invasions: what's what and the way forward. Trends in Ecology \& Evolution 28 :58-66. 
Stamatakis, A. 2014. RAxML version 8: a tool for phylogenetic analysis and post-analysis of large phylogenies. Bioinformatics $30: 1312-1313$.

Stenoien, H. K., C. B. Fenster, A. Tonteri, and O. Savolainen. 2005. Genetic variability in natural populations of Arabidopsis thaliana in northern Europe. Molecular ecology 14 :137-148.

$\mathrm{Su}$, N.-y., W. Ye, R. Ripa, R. H. Scheffrahn, and R. M. Giblin-davis. 2006. Identification of ChileanReticulitermes (Isoptera: Rhinotermitidae) Inferred from Three Mitochondrial Gene DNA Sequences and Soldier Morphology. Annals of the Entomological Society of America 99 :352-363.

Suarez, A. V., D. A. Holway, and T. J. Case. 2001. Patterns of spread in biological invasions dominated by long-distance jump dispersal: Insights from Argentine ants. Proceedings of the National Academy of Sciences 98 :1095-1100.

Suppo, C., C. Robinet, E. Perdereau, D. Andrieu, and A. G. Bagnères. 2018. Potential spreqd of the invasive North American termite, Reticulitermes flavipes, and the impact of climate warming. Biological Invasions $20: 905-922$.

Tsutsui, N. D., A. V. Suarez, D. A. Holway, and T. J. Case. 2000. Reduced genetic variation and the success of an invasive species. Proceedings of the National Academy of Sciences USA 97 :5948-5953.

United States Census Bureau. 1890. Report on Transportation Business in the United States at the Eleventh Census

van Kleunen, M., W. Dawson, F. Essl, J. Pergl, M. Winter, E. Weber, H. Kreft, P. Weigelt, J. Kartesz, M. Nishino, L. A. Antonova, J. F. Barcelona, F. J. Cabezas, D. Cárdenas, J. Cárdenas-Toro, N. Castaño, E. Chacón, C. Chatelain, A. L. Ebel, E. Figueiredo, N. Fuentes, Q. J. Groom, L. Henderson, Inderjit, A. Kupriyanov, S. Masciadri, J. Meerman, O. Morozova, D. Moser, D. L. Nickrent, A. Patzelt, P. B. Pelser, M. P. Baptiste, M. Poopath, M. Schulze, H. Seebens, W.-s. Shu, J. Thomas, M. Velayos, J. J. Wieringa, and P. Pyšek. 2015. Global exchange and accumulation of non-native plants. Nature 525 :100-103.

Vargo, E. L. 2003. Hierarchical analysis of colony and population genetic structure of the Eastern subterranean termite, Reticulitermes flavipes, using two classes of molecular markers. Evolution 57 :2805-2818.

Vargo, E. L. 2019. Diversity of termite breeding systems. Insects 10 :52.

Vargo, E. L. and C. Husseneder. 2009. Biology of subterranean termites: Insights from molecular studies ofReticulitermes and Coptotermes. Annual Review of Entomology $54: 379-403$.

Vargo, E. L., L. Leniaud, L. E. Swoboda, S. E. Diamond, M. D. Weiser, D. M. Miller, and A.-G. Bagnères. 2013. Clinal variation in colony breeding structure and level of inbreeding in the subterranean termites Reticulitermes flavipesand $R$. grassei . Molecular ecology 22 :1447-1462.

Verhoeven, K. J. F., M. Macel, L. M. Wolfe, and A. Biere. 2011. Population admixture, biological invasions and the balance between local adaptation and inbreeding depression. Proceedings of the Royal Society B: Biological Sciences278 :2-8.

Voisin, M., C. R. Engel, and F. Viard. 2005. Differential shuffling of native genetic diversity across introduced regions in a brown alga: Aquaculture vs. maritime traffic effects. Proceedings of the National Academy of Sciences of the United States of America $102: 5432-5437$.

Wares, J. P., A. R. Hughes, and R. K. Grosberg. 2005. Mechanisms that drive evolutionary change: insights from species introductions and invasions. Pages 229-257 in D. F. Sax, J. J. Stachowicz, and S. D. Gaines, editors. Species Invasions: Boon or Bane for Ecology and Evolution? Sinauer, Sunderland, MA, USA.

Weidner, H. 1937. Termiten in Hamburg. Z Pflanzenkrankh 47 :593-596. 


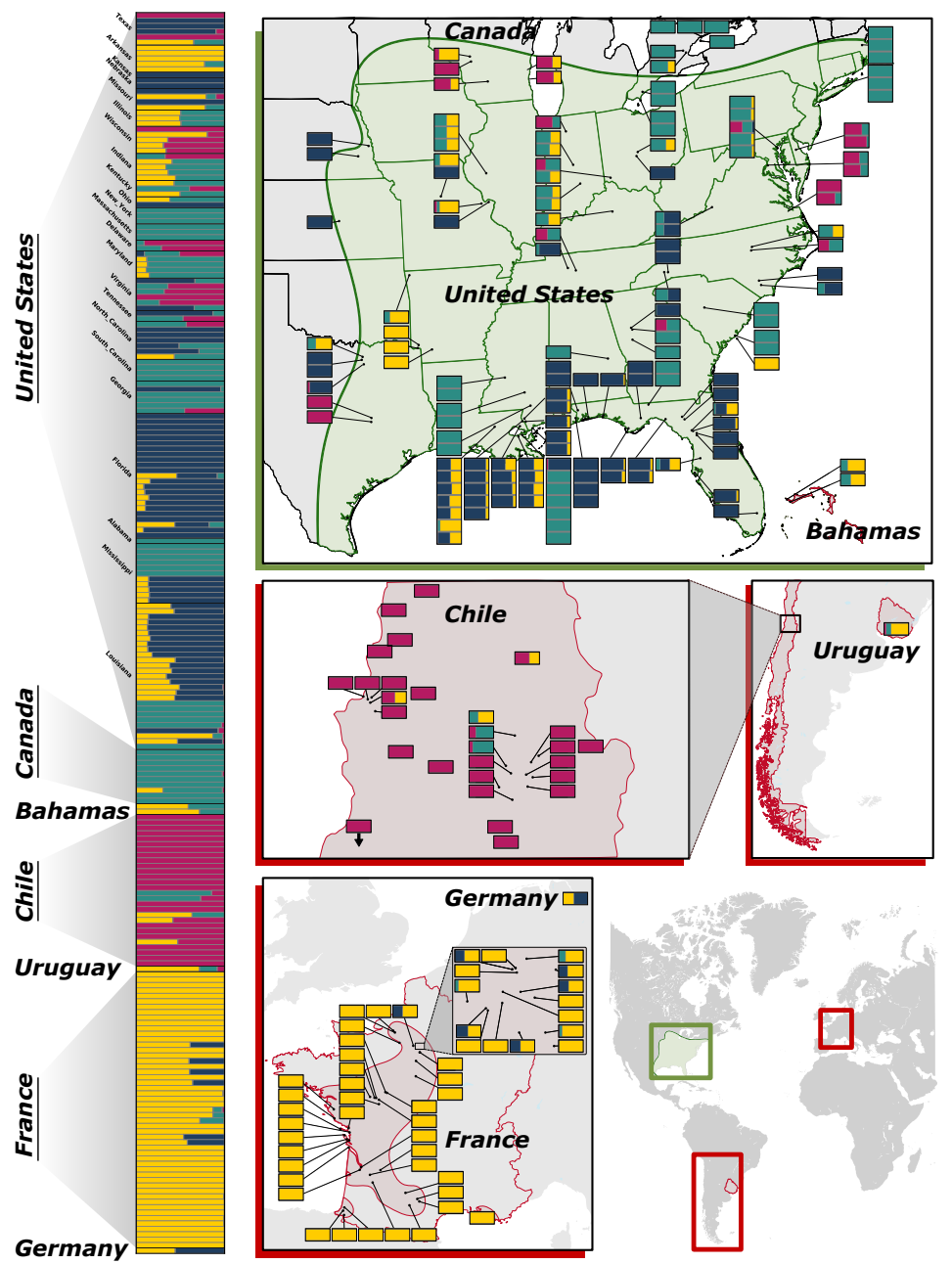

Figure 1: fastSTRUCTURE assignment for each individual of $R$. flavipes for $\mathrm{K}=4$. Each vertical bar represents an individual and each color represents a distinct genetic cluster. Individual fastSTRUCTURE assignments are geographically located in the native and introduced ranges of $R$. flavipes. 

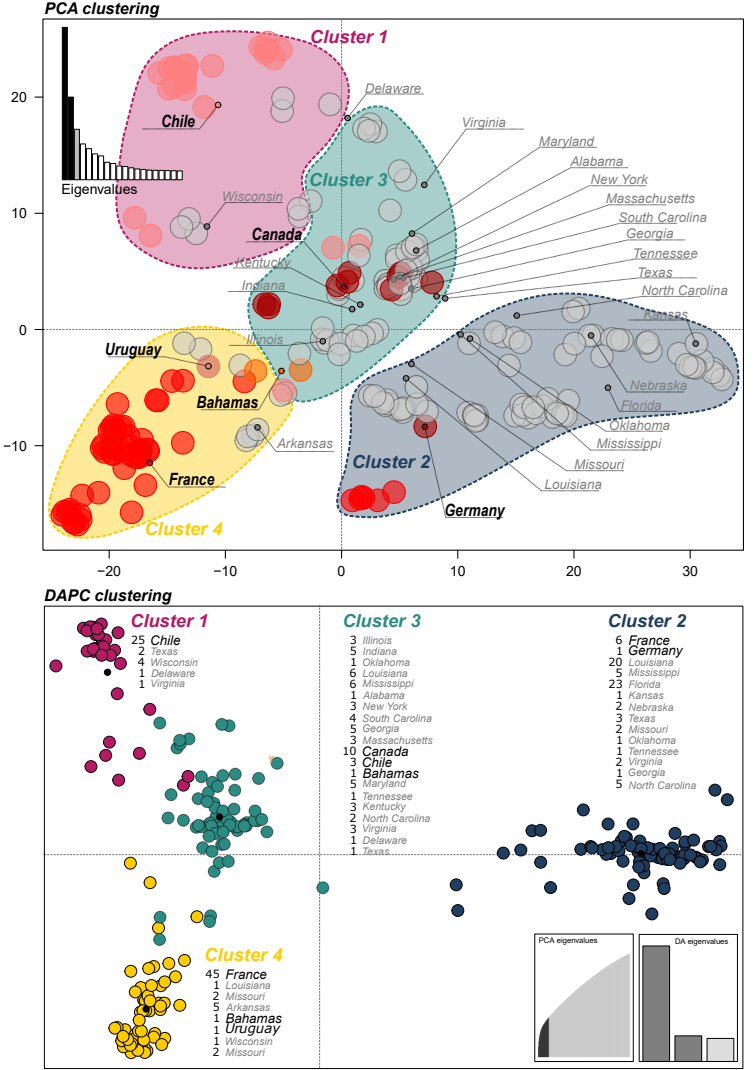

Figure 2: Principal Component Analysis (PCA) of Reticulitermes flavipes individuals. Individuals are grouped according the Discriminant Analysis of Principal Components (DAPC) with best support for $\mathrm{K}=4$ genetic clusters. 


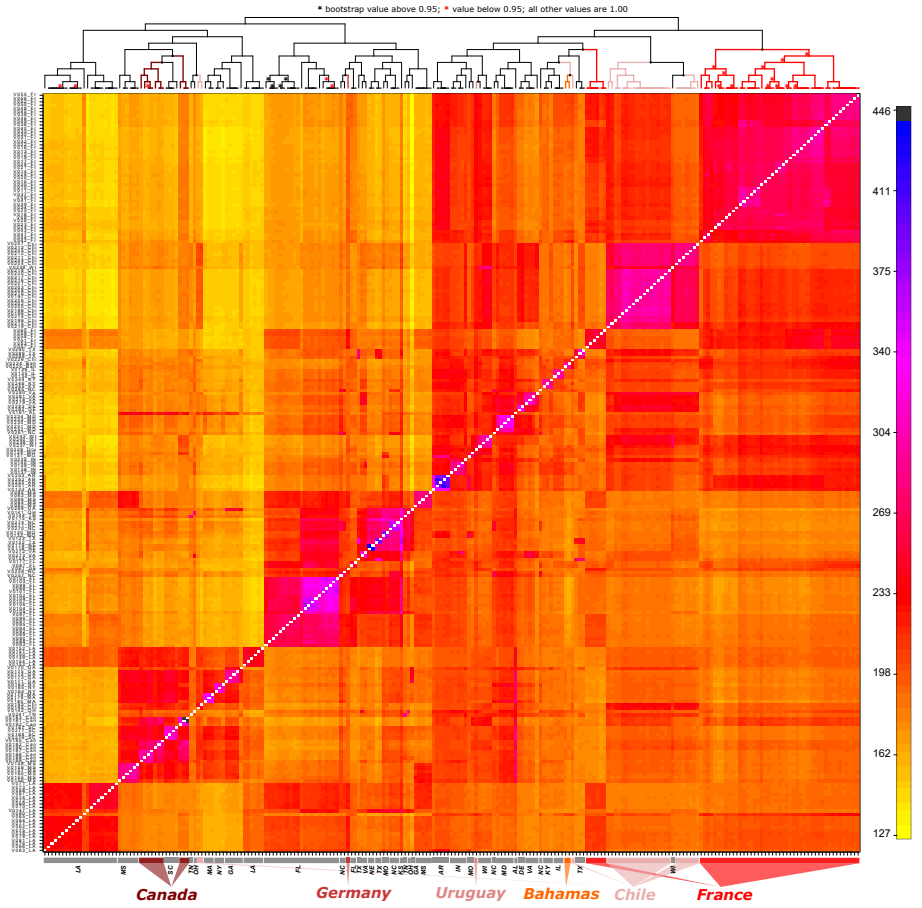

Figure 3: Co-ancestry matrix between each pair of individuals inferred using fineRADstructure. Each pixel represents a pair of individuals. Co-ancestry coefficients between two individuals are designated on a color spectrum. Low values are shown in yellow; higher values are shown in darker colors. 


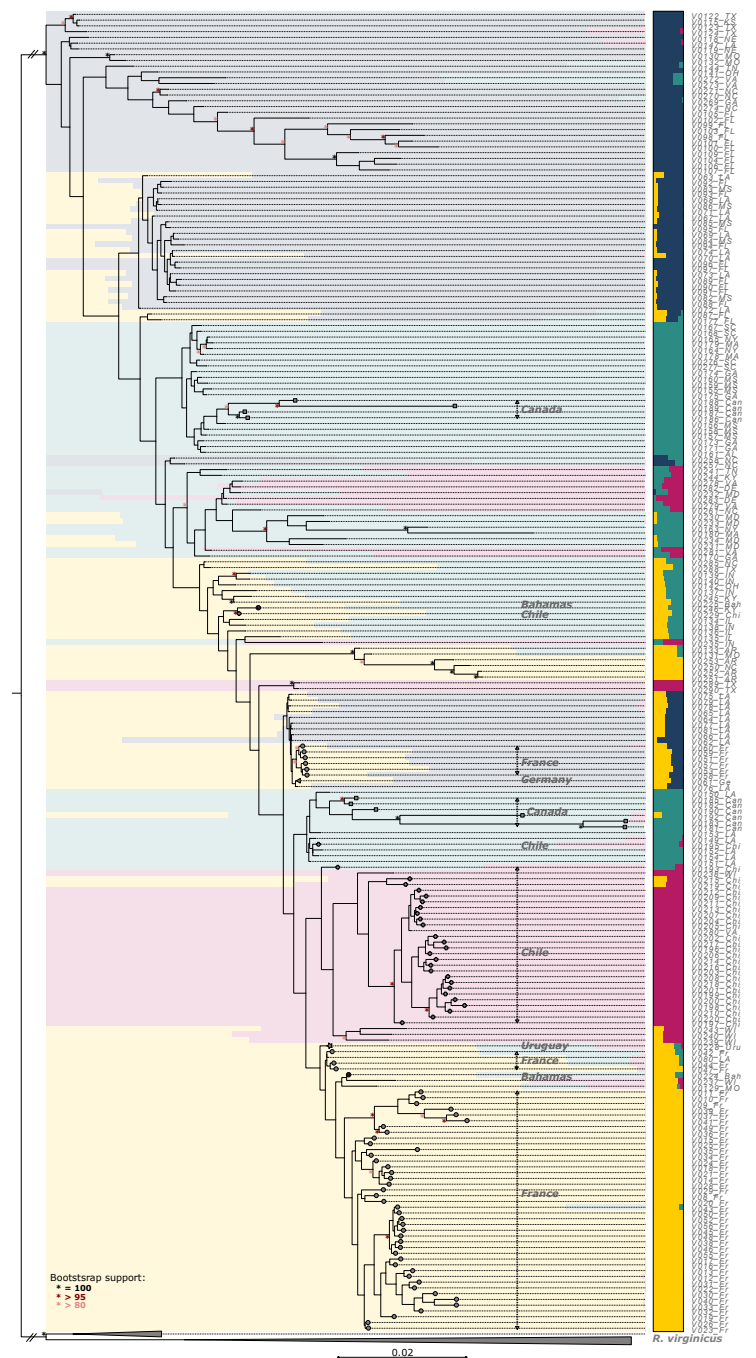

Figure 4: Maximum likelihood phylogenetic tree of Reticulitermes flavipes individuals from RAxML. Individuals are colored according to their fastSTRUCTURE assignments $(K=4)$. Samples from the introduced ranges are highlighted with an emphasized tip. The phylogenetic tree is rooted with $10 R$. virginicus samples. 


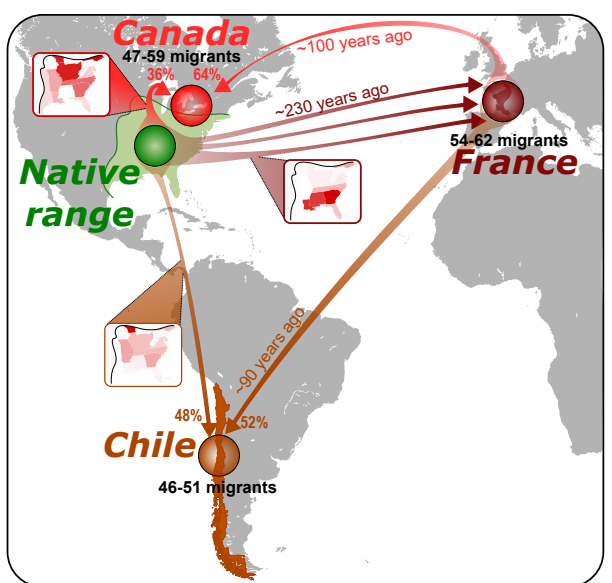

Figure 5: Graphical representation of the invasion pathway of Reticulitermes flavipes out of eastern USA inferred through $A B C$ RF in France, Canada and Chile.

For each introduction event out of the native range, the insets represent the most likely native source populations. All scenarios tested and results for each $A B C$ step, as well as all of the posterior parameter estimates, are provided in the Supplementary Information 